\title{
The effect of sintering temperature on the porosity and compressive strength of corundum
}

\author{
${ }^{1}$ University Center of Relizane, Department of Mechanical Engineering, Relizane, Algeria, E-mail: bendaoudi.seif@gmail.com \\ ${ }^{2}$ University of Sidi Bel Abbes, Departement of Mechanical Engineering, Sidi Bel Abbes, Algeria, E-mail: bounazef@yahoo.com, \\ djeffalal@yahoo.fr
}

\begin{abstract}
:
Porous corundum ceramic samples were sintered at various temperatures in the range of $1350-1550^{\circ} \mathrm{C}$. The effect of the sintering temperature on the porosity rate and compressive strength of corundum samples were investigated. The porosity rates were of the order of 3.3-38\% and the high-density sample was obtained at a relatively high temperature. However, an increase of compressive strength by more than 6 times was observed with the sintering temperature rise. The Young's modulus increased remarkably from 40.49 to $302.15 \mathrm{GPa}$, which is related to the corresponding decrease of porosity rate.
\end{abstract}

Keywords: corundum, porosity rate, sintering temperature, Young's modulus

DOI: $10.1515 /$ jmbm-2018-0018

\section{Introduction}

Corundum, a form of alumina, is used to manufacture various components and mechanical, electrical and electronics parts. It is known for its relatively high hardness, high strength and low thermal conductivity compared to other ceramics, it has become a good material for sandpaper and grinding tools. Corundum products are usually made by sintering alumina powder at high temperature $\left(>1300^{\circ} \mathrm{C}\right)$. It has been demonstrated that the sintering temperature has great influence on the properties of the alumina foamed ceramics [1]. As a consequence, the strength of corundum is not a strict material property but is dependent on the controlled sintering temperature [2], [3], [4]. On the other hand, many studies have reported that the decrement of strength relates directly to the microstructure of porous ceramics which is influenced by the fabrication methods [5], [6], [7], [8], [9].

The intention of the present work was to study the effect of sintering temperature variation on porosity rate and mechanical behavior, under nominal compression, of porous corundum ceramic.

\section{Experimental}

The sintering technique under high pressure was applied to fabricate bulk loads of alumina ceramics. This method typically consists of preparing a powder of $95 \mathrm{wt} . \% \alpha-\mathrm{Al}_{2} \mathrm{O}_{3}$ and $5 \mathrm{wt} . \%$ additives and then molding and sintering at different temperatures of $1350,1400,1500$, and $1550^{\circ} \mathrm{C}$, with which we had obtained samples of porous corundum at different rates of porosity of 38\%,32.7\%,7.7\% and 3.3\%. The measurement of porosity was done as a function of the presence of pores on a cross-section surface using Scion Image software (Scion Corporation, MD, USA) and then the percentages were estimated by the means of several surface measurements of the same sample. The samples obtained are summarized in Table 1.

Table 1: A summary of the obtained samples.

\begin{tabular}{lrrrr}
\hline Samples no. & A & B & C & D \\
\hline Sintered temperature $\left({ }^{\circ} \mathrm{C}\right)$ & 1350 & 1400 & 1500 & 1550 \\
Rate of porosity $(\%)$ & 38 & 32.7 & 7.7 & 3.3 \\
Young's modulus (GPa) & 40.49 & 94.93 & 249.37 & 302.15 \\
Strength (MPa) & 149.02 & 239.22 & 486.27 & 552.94 \\
\hline
\end{tabular}

Seif-Eddine Bendaoudi is the corresponding author.

(O2018 Walter de Gruyter GmbH, Berlin/Boston. 
The study of the temperature effect on the mechanical behavior was accomplished by analyzing the variation of Young's modulus of the samples. This is determined as a function of compression test results (stress and strain) by applying a uniaxial load at room temperature. The test measurements were conducted as follows: for every given rate of porosity, a compressive stress and strain were measured several times to determinate the maximum stress and strain supported by a material before rupture.

\section{Results and discussion}

\subsection{Effect of the sintering temperature on the porosity rate}

Figure 1 shows the variations of the porosity rate of corundum ceramics at different sintering temperatures in the range of $1350-1550^{\circ} \mathrm{C}$. A high porosity of $38 \%$ was observed for samples sintered at low temperatures. However, an increase in sintering temperature was accompanied with a decrease in the average pore size, so the porosity rate was reduced due to the process of sintering densification that results in the gradual occupation of the pores by the grains of the corundum. The low porosity of 3.3\% was obtained at high temperatures.

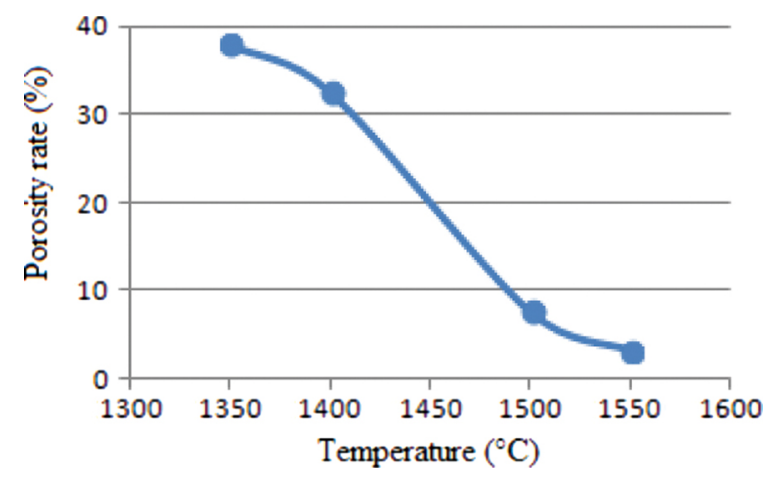

Figure 1: The porosity rate of samples obtained at different temperatures.

\subsection{Effect of the sintering temperature on the Young's modulus}

The Young's modulus, which describes the ceramic resistance to elastic deformation, exhibits almost linear dependence on the sintering temperature, as shown in Figure 2. The samples of corundum ceramics obtained at a higher sintering temperature of $1550^{\circ} \mathrm{C}$, was characterized by a high Young's modulus of 302.15 GPa. However, the values of this last was reduced relatively for samples sintered at relatively low temperatures from 1500 to $1350^{\circ} \mathrm{C}$. It is worth reminding that the uniaxial compressive load is applied to the samples until the rupture moment takes place. It is clear that the quality of the compressive strength was improved to a good level with the increase of sintering temperature, and the material becomes less rigid with the decrease in temperature.

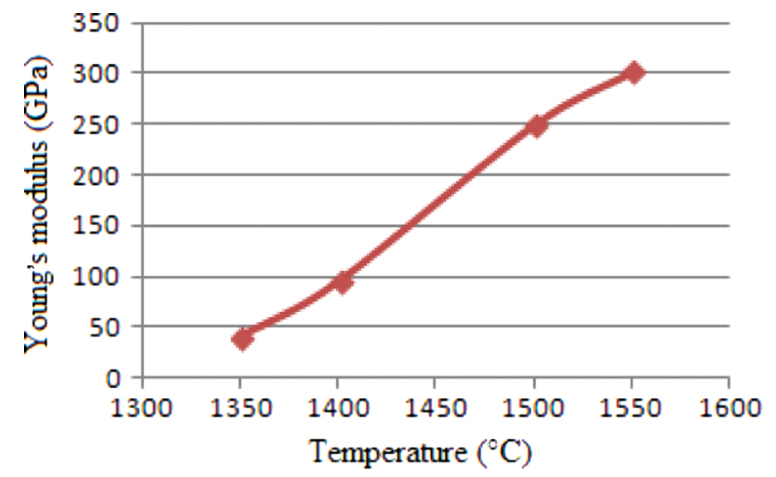

Figure 2: Variation of Young's modulus as a function of temperature. 


\subsection{Variation of the compression strength as a function of the porosity rate}

On the other hand, the variation curve, obtained after testing ceramics with different porosity levels in compression, showed that their behavior depended on the pore presence rate. The elastic modulus was almost linear depending on the porosity rate of ceramic samples, as shown in Figure 3. This dependence seems reasonable, as was discussed in previous curves, the sintering temperatures affect the porosity rate and Young's modulus of ceramic samples, so consequently, it shows that Young's modulus also depends on the porosity rate.

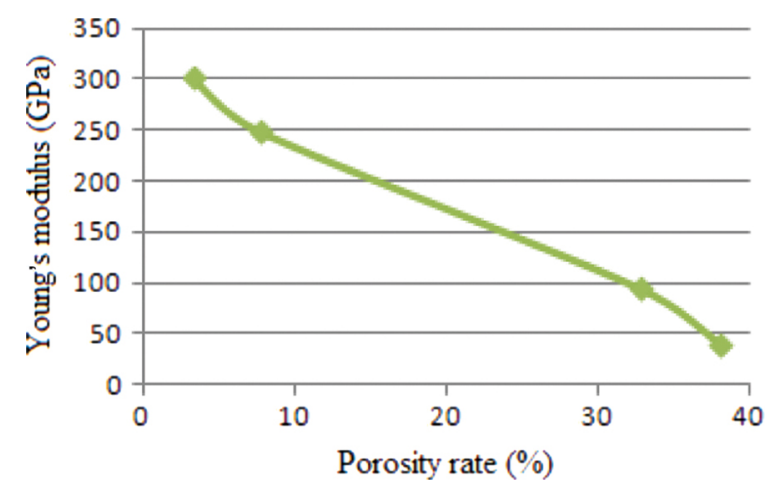

Figure 3: Variation of Young's modulus as a function of porosity rate.

The samples with a high porosity of 3.3\%, break down after reaching the compression strength limit and showed a low elastic modulus, of less than $50 \mathrm{GPa}$, compared to the samples with a low porosity rate of $38 \%$, which provides a high compression strength limit and consequently a large Young's modulus greater than 300 GPa.

\section{Conclusion}

Porous corundum ceramics sintered at various temperatures in the range of $1350-1550^{\circ} \mathrm{C}$, were investigated. The sintering temperature significantly influenced the porosity rate and pore size distribution in the samples.

The analysis of elastic modulus curves of porous corundum ceramics (within the porosity range of 3.3\%$38 \%$ ) showed that the increase in sintering temperature affects the compression strength of ceramic samples and increases their Young's modulus which varied between 40 and $300 \mathrm{GPa}$.

Therefore, it is possible to adjust the sintering temperature, to control the porosity rate and thus the compressive strength of porous corundum ceramics in order to reach the performance requirements both economically and efficiently.

\section{Acknowledgments}

This work was financially supported by LMNEPM Laboratory of Numerical and Experimental Modeling of Mechanical Phenomena and by university center of Relizane.

\section{References}

[1] Jia C, Liu ], Ding R, Teng D, Feng L. Effects of the Sintering Temperature on the Structure and Properties of the Alumina Foamed Ceramics. MATEC Web of Conferences, 67(SMAE 2016). DOI: https://doi.org/10.1051/matecconf/20166704011.

[2] Ashby MK, Sammis CG. J. Pure Appl. Geophys. 1990, 133, 489-521.

[3] Zouboulis ES, Grimsditch M. J. Appl. Phys. 1991, 70, 772-776.

[4] Keke K, Li Y, Zhao Y, Li S, Li Y, Sang S. J. Mater. Lett. 2016, 165, 19-21. DOI: 10.1016/j.matlet.2015.11.097.

[5] Deng Z-Y, Yang J-F, Beppu Y, Ando M, Ohji T. J. Am. Ceram. Soc. 2002, 85, 1961-1965. DOI: 10.1111/j.1151-2916.2002.tboo388.x.

[6] Kim H-W, Lee S-Y, Bae C-J, Noh Y-J, Kim H-E, Kim H-M, Ko ]S. J. Biomater. 2003, 24, 3277-3284. DOI: 10.1016/S0142-9612(03)00162-5.

[7] Jun I-K, Koh Y-H, Kim H-E. J. Mater. Lett. 2006, 60, 878-882. DOI: 10.1016/j.matlet.2005.10.037.

[8] Rambo CR, Cao ], Sieber H. J. Mater. Chem. Phys. 2004, 87, 345-352. DOI: 10.1016/j.matchemphys.2004.05.031.

[9] Tang F, Fudouzi H, Uchikoshi T, Sakka Y. J. Eur. Ceram. Soc. 2004, 24, 341-344. DOI: 10.1016/So955-2219(03)00223-1. 